\title{
Proceeding
}

Supplementary Issue: Autumn Conferences of Sports Science. Costa Blanca Sports Science Events, 18-19 December 2020. Alicante, Spain.

\section{The effect of eccentric hamstring strength on the change of direction speed of professional ice hockey players}

\author{
ROMAN ŠVANTNER ${ }^{1,2}$, DAVID BRÜNN ${ }^{1,2}$, DÁVID LIŠKKA1 \\ ${ }^{1}$ Department of Physical Education and Sports, Faculty of Arts, Matej Bel University in Banská Bystrica, \\ Slovakia \\ ${ }^{2}$ Fit Factory, Nemce, Slovakia
}

\begin{abstract}
Introduction: Ice hockey is a sport that requires high acceleration of players for optimal performance. The speed of athletes is influenced by several factors. The aim of this research was to determine the effect of the eccentric hamstring strength of ice hockey players on speed with directional changes. Methods: The sample consisted of 15 members of the Slovak national ice hockey team; the average age was 27, the average height was $186.46 \mathrm{~cm}(\mathrm{SD} \pm 5.04)$, and the average body weight was $90.87 \mathrm{~kg}(\mathrm{SD} \pm 5.91)$. The players completed a NordBord Nordic Hamstring Test to determine the eccentric force of their hamstrings. We used the 5-10-5 test to determine their speed with directional changes. Results: We measured a small correlation $(.129, p>$ .05) between the eccentric muscle strength of hamstrings and the speed with directional changes in the 5 10-5 test. The average ice hockey player's hamstring strength was $456.13 \mathrm{~N}(\mathrm{SD} \pm 51.28)$ and the average time achieved in the 5-10-5 test was 4.984s (SD \pm 0.15$)$. We also found a small correlation between right hamstring force and the right side of the $5-10-5$ test $(r=.228, p>.05)$, and there was no correlation between left hamstring force and the left side of the $5-10-5$ test $(r=-.004, p>.05)$. Conclusion: According to our study, hamstring eccentric strength does not correlate with speed directional changes. However, more intervention studies are needed.
\end{abstract}

Keywords: Eccentric hamstring strength; Speed with directional changes.

Cite this article as:

Švantner, R., Brünn, D., Líška, D., Sýkora, J., \& Pupiš, M. (2021). The effect of eccentric hamstring strength on the change of direction speed of professional ice hockey players. Journal of Human Sport and Exercise, 16(2proc), S353-S360. doi:https://doi.org/10.14198/ihse.2021.16.Proc2.19

Corresponding author. Department of Physical Education and Sports, Faculty of Arts, Matej Bel University in Banská Bystrica, Slovakia. https://orcid.org/0000-0002-5700-1341

E-mail: david.liska27@gmail.com

Abstract submitted to: Autumn Conferences of Sports Science. Costa Blanca Sports Science Events, 18-19 December 2020. Alicante, Spain.

JOURNAL OF HUMAN SPORT \& EXERCISE ISSN 1988-5202

(C) Faculty of Education. University of Alicante

doi:10.14198/jhse.2021.16.Proc2.19 


\section{INTRODUCTION}

A typical hockey game is very dynamic and involves exposure to intermittent high-intensity activity, typically in 30 second shifts (Bond et al., 2018; Vigh-Larsen et al., 2020). Players require an extensive, yet balanced range of physiological capabilities to compete at the highest level (McGuinness et al., 2020). Both highvelocity collisions and unpredicted changes of directions are common (McGuinness et al., 2020). This demand for ability requires the athlete to be able not only to accelerate and decelerate repeatedly, but also to change direction intermittently while remaining in motion (Chaabène et al., 2012). The ability to quickly change direction on the field or court separates the great athletes from the good ones. This fact also applies to ice hockey players.

Ice skating is a series of muscle contractions that generate the force to move the skater across the ice (Polglaze et al., 2020). The stronger those muscles are, the more force they can generate and the faster the skater will be. The capacity to quickly change direction while sprinting, also widely known as a cutting manoeuvre or change of direction speed, is an important performance determinant in many team sports. In modern ice hockey, there are so many situations where the players have to change the direction of skating in the game for different purposes (Robbins et al., 2020). For example, when they want to evade an opponent in an attack, or in the case that they lose the puck in the attacking area and immediately have to turn and skate back. When changing direction or taking off after a loose puck, more powerful athletes are able to generate their maximum force more quickly, translating into a more explosive first few strides and an advantage over less powerful athletes.

The eccentric strength of hamstrings plays an important role in sprinting (Hedayatpour \& Falla, 2012; Vogt \& Hoppeler, 2014). Sprint biomechanics require the significant activation of eccentric muscle strength during the swing phase. Sprinting is essential for successful sport performance (Sharma \& Kailashiya, 2018). Eccentric muscle strength is especially needed to decelerate and stabilize the body during tasks.

The main muscles which are engaged in skating are the glutes (m. gluteus maximus, $\mathrm{m}$. gluteus medius, $\mathrm{m}$. gluteus minimus), the hamstrings (m. semitendinosus, $m$. semimembranosus, $m$. biceps. femoris), the $m$. quadriceps ( $m$. quadriceps $-m$. rectus femoris, $m$. vastus medialis, $m$. vastus lateralis, $m$. vastus intermedius), and the abdominal muscles ( $m$. rectus abdominis, $m$. internal oblique, $m$. external oblique, $m$. erector spinae - m. iliocostalis, m.longissimus, $m$. spinalis) (Buckeridge et al., 2015). The m. gluteus maximus and the $\mathrm{m}$. quadriceps muscle groups are mainly responsible for force production during the push phase (Shell et al., 2017). The $\mathrm{m}$. biceps femoris plays an important role during the push phase and especially in the glide phase, where it is active in an eccentric character of work. Hockey players are forced to develop the strength of their glute and hamstring muscles because, in addition to force generation, they maintain the strength and balance between knee and hip joints.

Hence, this is the reason why change of direction speed is one of the most important abilities in this sort of sport. In our study, we focused on the role of a specific muscle group, the hamstrings, in the mechanics of deceleration and re-acceleration. The question is whether it is mainly the eccentric strength of this muscle group that is one of the contributing factors to change of direction speed.

\section{Aim}

The aim of this study was to determine the effect of the eccentric hamstring strength of ice hockey players on speed with directional changes. 


\section{MATERIALS AND METHOD}

\section{The sample}

The sample consisted of 15 members of the Slovak national ice hockey team; the average age was 27, the average height was $186.46 \mathrm{~cm}(S D \pm 5.04)$, and the average body weight was $90.87 \mathrm{~kg}(\mathrm{SD} \pm 5.91)$. The research took place in July 2019, with assistance from the FiT Factory facility in Nemce, Banská Bystrica.

\section{NordBord}

We chose NordBord to test eccentric hamstring strength. This system evaluates the average and maximal force by applying force to ankle hooks to two force cells which are primarily generated by athletes' hamstrings. The NordBord Hamstring Testing System is a device based on the measurement of eccentric and isometric hamstring strength. The majority of the NordBord area consists of an area for athletes to kneel on. The ankle hooks include a sensor that measures the force of the muscle activity (in Newtons). To successfully complete the test, the NordBord sensors must be in a perpendicular position to the ground.

Hockey players performed 2 tries of maximal eccentric effort with both limbs at the same time. Before this specific test, the athletes performed their standard "pre-strength training" warm-up. In between these two tries the hockey players had a 1-minute break.

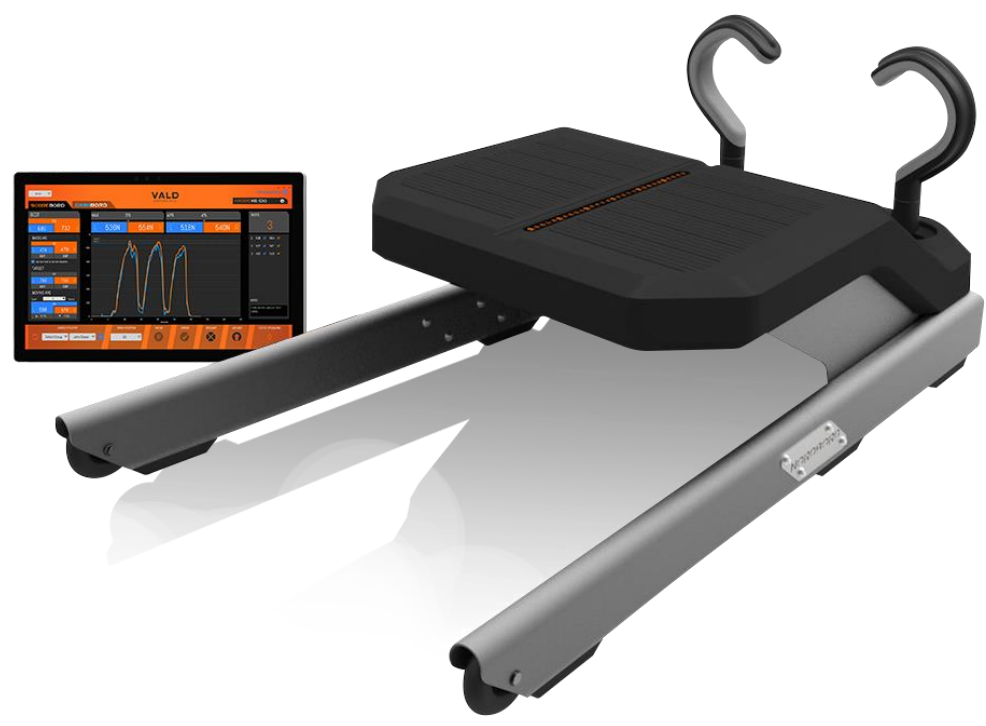

Figure 1. NordBord Hamstring Testing system.

\section{5-10-5 Shuttle}

The 5-10-5 shuttle test consists of rapid directional changes in a linear plane. This test has also been referred to as the pro-agility test. It is used as part of player assessment in different sports. The setup for this test is very simple since it only requires three cones that are placed 5 yards $(5 \mathrm{~m})$ apart in a straight line. The meter distances were measured, and the lines were marked at 0.5- and 10-meter points. One pair of Microgate photocells was used and placed exactly at a 5-meter distance. The players started in the middle, right between the photocell 's beam, in a low stance with one hand placed on the ground facing the photocell. When the player was ready, he started sprinting 5 meters in the same direction as the hand that was placed on the ground, followed by crossing the line with the leg opposite the hand that was placed, cutting, and changing direction to the opposite side. When he ran 10 meters, he cut on the same leg again and ran back 
to the middle at full speed. Each player performed two attempts on each side. Microgate Polifemo photocells work as a coaxial optical system. Also, the Polifemo line employs an intelligent link to a timer using a standard 2-wire connection.

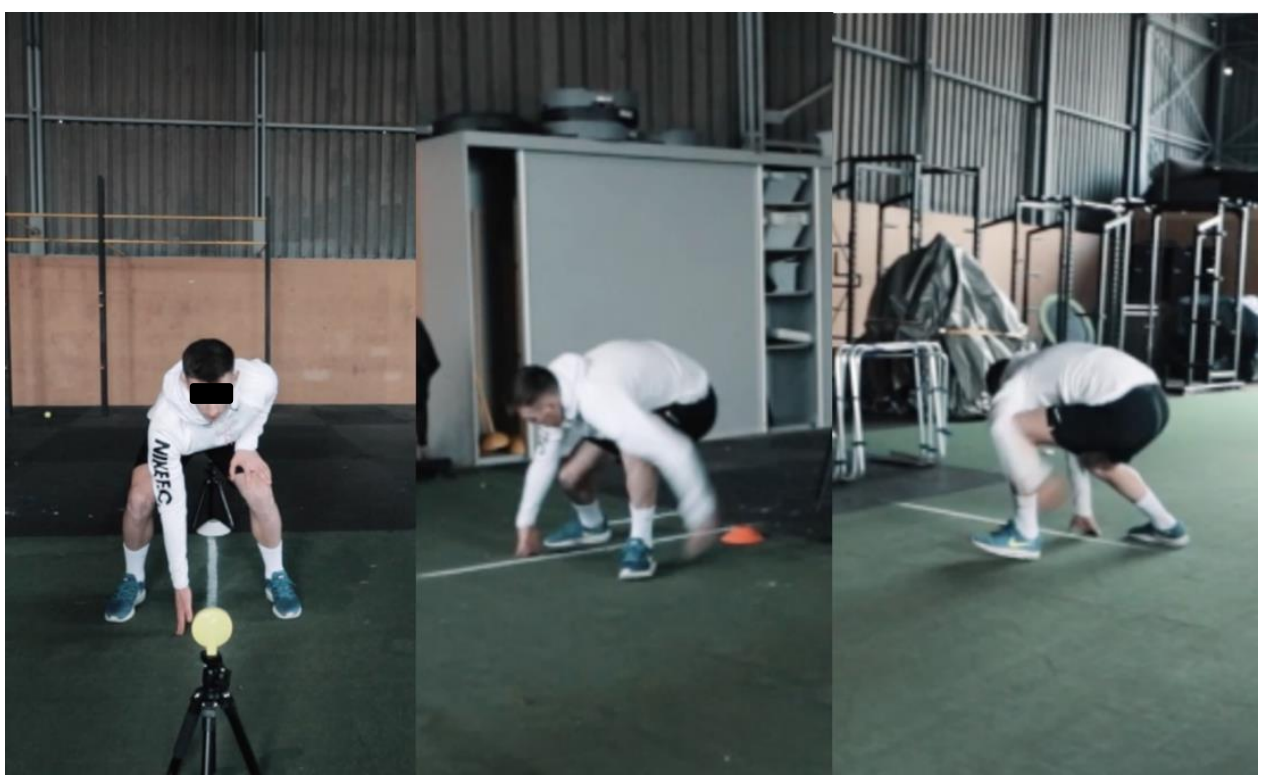

Figure 2. 5-10-5 Shuttle run test.

\section{Statistical processing}

We used Pearson Correlation. We have clarified the correlation relationship between the variables using a correlation matrix and graphically. We used a significance level equal to $a=.05$. We have created a correlation analysis using RStudio statistical software. We calculated the data distribution in IBM SPSS software V19.

\section{RESULTS}

15 members of the Slovak national ice hockey team participated in tests to measure eccentric hamstring strength as well as a test to determine speed with the change of direction. The results are presented in Table 1.

Table 1. Test performance summary.

\begin{tabular}{lccccc}
\hline & $\begin{array}{c}\text { Left Hamstring } \\
\text { Force (N) }\end{array}$ & $\begin{array}{c}\text { Right Hamstring } \\
\text { Force (N) }\end{array}$ & Difference L:R (\%) & $\mathbf{5 - 1 0 - 5 ~ R ( s e c . )}$ & $\mathbf{5 - 1 0 - 5 ~ L ~ ( s e c . ) ~}$ \\
\hline Average & 452.93 & 459.33 & 0.15 & 4.95 & 5.02 \\
SD & 48.8 & 56.3 & 5.0 & 0.16 & 0.13 \\
\hline
\end{tabular}

The average team score and the score variability is presented via the standard deviation value.

Most of the hockey players had a stronger dominant right leg and achieved a faster time on the right side of the 5-10-5 test. Specifically, we measured an average left hamstring force of $452.93 \mathrm{~N}$ (SD 48.8) and right hamstring force of $459.33 \mathrm{~N}$ (SD 56.3). The difference between the average hamstring force of both limbs was $0.15 \%$ (SD 5.0). The average time of the $5-10-5$ shuttle run test was $4.95 \mathrm{~s}$ (SD 0.16) for the right side 
and $5.02 \mathrm{~s}$ (SD 0.13) for the left side. We calculated the data distribution in IBM SPSS software V19. The Shapiro-Wilk test results revealed that the data were normally distributed within a sample in each variable. Therefore, we used a Pearson correlation non-parametric test $(\alpha=.05)$ to calculate if any correlation exists between hip adductor isometric force and speed with changes of direction. Interpretation of the Pearson correlation test: $r=.10$ small (weak) relation, $r=.30$ medium (strong) relation, $r=.70$ great (strong) relation. The results are presented in Table 2.

Table 2 Pearson correlation results.

\begin{tabular}{lc}
\hline Right leg hamstring force vs Right side COD test & Pearson correlation results \\
Left leg hamstring force vs Left side COD test & $r=.228, p>.05$ \\
Right and Left leg hamstring force vs COD test & $r=.004, p>.05$ \\
\end{tabular}

Based on Table 2, we can declare that there is only small (weak) correlation between right leg hamstring force and the ability to change direction with the right leg $(r=.228, p>.05)$. We can also declare a small correlation between the average force of the left and right hamstrings and the ability to change direction to the left and right sides $(.129, p>.05)$. There is no correlation between left leg hamstring force and the left side of the change of direction test $(-.004, p>.05)$.

\section{DISCUSSION}

When it comes to speed with changes of direction, most of the players are able to cut and change direction faster on the right side (meaning decelerate and re-accelerate with the right leg).

Therefore, we wanted to determine whether hamstring eccentric strength level has any effect on speed with changes of direction.

In the study, hamstrings' eccentric strength did not correlate with sprint speed based on a $30 \mathrm{~m}$ sprint. A potential explanation can be that it is difficult to isolate one factor which would relate to speed when changing direction. This study demonstrates just a small correlation $(.129, p>.05)$ between hamstring strength and speed with directional changes (5-10-5 test). Our study provides a new insight into the relationship between speed with directional changes and hamstring strength because no other research has dealt with the same research problem.

The generalizability of the results is limited by the fact that we only used one test (the NordBord eccentric Nordic strength test) to proclaim the final correlation. NordBord offers many other testing positions and options (Isometric $30^{\circ}$ test, Isometric prone test, etc.) that can be used in later research. The next question for us is if there is possibly positive correlation between change of direction 5-10-5 tests and isometric hamstring tests. Our findings challenge the existing assumptions and therefore create space for further research.

The results of our study indicate that there are other muscle groups and movement qualities that make a difference in final performance. This research illustrates little to no association between the chosen variables, but the question of the most important muscle group involved in changing direction remains. Further research is needed to determine the relationship between the strength of the hamstring muscle group and speed with changes of direction. Eccentric exercise is not the only type of exercise used by hockey players to improve speed. Another type of exercise is plyometric exercise. Singh et al. (2018) tested the effect of plyometric 
training on speed and change of direction Ability in Elite Field Hockey Players. The sample consisted of seventeen elite male and female field hockey players who were randomly allocated into either low-to-high (L$H, n=8)$ or high-to-low $(H-L, n=9)$ training groups. Differences between the groups for $10 m$ and $20 m$ sprint performance failed to reach statistical significance, and no significant differences were observed within or between groups for 5-10-5 times.

Timmins et al. (2016) in the 2014-2015 realized preseason and season tests, which showed a correlation between hamstring strength and the risk of hamstring strain injuries in football. Players whose eccentric strength (in the Nordic Hamstring test, measured on NordBord system) was under 337 Newtons (N) of force at the end of the 2014-15 preseason, had on average a 4.4 times higher chance of having a hamstring strain injury in the upcoming season. Their research also showed that eccentric hamstring strength could also overcome unmodifiable risk factors such as age and previous injury.

A previous hamstring injury increases the risk of return by about $16 \%$ according to Brukner et. al. (2015). Specifically, players scoring over 500 (N) on each leg showed indistinguishable levels of hamstring injury risk. Early detection of strength deficits or laterality allows appropriate intervention as required (Bahr et al., 2015). Part of these assessments also indicates when an athlete is ready for increased resistance in exercise, progression of exercise, or higher workloads in general. The aim of the study by Liška et al. (2019) was to test the size of eccentric muscle strength in professional hockey players and football players. The tested group consisted of 30 professional hockey players and 30 football players. The average values of eccentric muscle strength in hockey players were $419.8 \mathrm{~N}$ on the left hamstring and $420.9 \mathrm{~N}$ on the right hamstring. For football players, the average values of eccentric muscle strength reached the following values: left hamstring $419.6 \mathrm{~N}$ and right hamstring $428.6 \mathrm{~N}$. There was no statistically significant difference between football players and hockey players in terms of the size of the hamstrings' eccentric strength.

The limitation of this study was the use of observational methodology. We selected Slovak national hockey players and we tested the correlation between speed with changes of direction and the eccentric muscle strength of hamstrings. Slovak national hockey players represent a valid sample from the point of view of the quality of the hockey players because they are part of the national team. However, it is difficult to do an intervention study directly, which would help to clarify the issue. This is because each hockey player has his own club and his own training process, which cannot be influenced. We chose correlation testing for it. A limiting factor in testing the correlation of force and velocity with changes in direction is that velocity is affected by several factors and it is difficult to expect a positive correlation with only one factor.

\section{CONCLUSION}

According to our study, hamstring strength does not correlate with speed directional changes. However, more intervention studies are needed.

\section{REFERENCES}

Bahr, R., Thorborg, K., \& Ekstrand, J. (2015). Evidence-based hamstring injury prevention is not adopted by the majority of Champions League or Norwegian Premier League football teams: The Nordic Hamstring survey. British Journal of Sports Medicine, 49(22), 1466-1471. https://doi.org/10.1136/bjsports-2015-094826 
Bond, C. W., Bennett, T. W., \& Noonan, B. C. (2018). Evaluation of Skating Top Speed, Acceleration, and Multiple Repeated Sprint Speed Ice Hockey Performance Tests. Journal of Strength and Conditioning Research, 32(8), 2273-2283. https://doi.org/10.1519/JSC.0000000000002644

Brukner, P. (2015). Hamstring injuries: Prevention and treatment-an update. British Journal of Sports Medicine, 49(19), 1241-1244. https://doi.org/10.1136/bjsports-2014-094427

Buckeridge, E., LeVangie, M. C., Stetter, B., Nigg, S. R., \& Nigg, B. M. (2015). An On-Ice Measurement Approach to Analyse the Biomechanics of Ice Hockey Skating. PLoS ONE, 10(5). https://doi.org/10.1371/journal.pone.0127324

Hedayatpour, N., \& Falla, D. (2012). Non-uniform muscle adaptations to eccentric exercise and the implications for training and sport. Journal of Electromyography and Kinesiology: Official Journal of the International Society of Electrophysiological Kinesiology, 22(3), 329-333. https://doi.org/10.1016/j.jelekin.2011.11.010

Chaabène, H., Hachana, Y., Franchini, E., Mkaouer, B., \& Chamari, K. (2012). Physical and physiological profile of elite karate athletes. Sports Medicine (Auckland, N.Z.), 42(10), 829-843. https://doi.org/10.1007/BF03262297

Liška, D., Švantner, R., Brünn, D., \& Pupiš, M. (2019). A comparison of eccentric hamstrings muscle strength in elite hockey players and football players and its impact on the risk of hamstring strains. Zdravotnicke Listy, 7(3), 37-44.

McGuinness, A., Passmore, D., Malone, S., \& Collins, K. (2020). Peak Running Intensity of Elite Female Field Hockey Players During Competitive Match Play. Journal of Strength and Conditioning Research. https://doi.org/10.1519/JSC.0000000000003582

Polglaze, T., Dawson, B., Buttfield, A., \& Peeling, P. (2020). Using the interaction of speed and acceleration to detect repeated-sprint activity in team sports. Journal of Sports Sciences, 38(19), 2186-2192. https://doi.org/10.1080/02640414.2020.1776464

Robbins, S. M., Renaud, P. J., Maclnnis, N., \& Pearsall, D. J. (2020). The relationship between trunk rotation and shot speed when performing ice hockey wrist shots. Journal of Sports Sciences, 1-9. https://doi.org/10.1080/02640414.2020.1853336

Sharma, H. B., \& Kailashiya, J. (2018). Effects of 6-Week Sprint-Strength and Agility Training on Body Composition, Cardiovascular, and Physiological Parameters of Male Field Hockey Players. Journal of Strength and Conditioning Research, 32(4), 894-901. https://doi.org/10.1519/JSC.0000000000002212

Shell, J. R., Robbins, S. M. K., Dixon, P. C., Renaud, P. J., Turcotte, R. A., Wu, T., \& Pearsall, D. J. (2017). Skating start propulsion: Three-dimensional kinematic analysis of elite male and female ice hockey players. Sports Biomechanics, 16(3), 313-324. https://doi.org/10.1080/14763141.2017.1306095

Singh, J., Appleby, B. B., \& Lavender, A. P. (2018). Effect of Plyometric Training on Speed and Change of Direction Ability in Elite Field Hockey Players. Sports, 6(4). https://doi.org/10.3390/sports6040144

Timmins, R. G., Bourne, M. N., Shield, A. J., Williams, M. D., Lorenzen, C., \& Opar, D. A. (2016). Short biceps femoris fascicles and eccentric knee flexor weakness increase the risk of hamstring injury in elite football (soccer): A prospective cohort study. British Journal of Sports Medicine, 50(24), 15241535. https://doi.org/10.1136/bjsports-2015-095362

Vigh-Larsen, J. F., Ermidis, G., Rago, V., Randers, M. B., Fransson, D., Nielsen, J. L., Gliemann, L., Piil, J. F., Morris, N. B., DE Paoli, F. V., Overgaard, K., Andersen, T. B., Nybo, L., Krustrup, P., \& Mohr, M. (2020). Muscle Metabolism and Fatigue during Simulated Ice Hockey Match-Play in Elite Players. Medicine and Science in Sports and Exercise, 52(10), 2162-2171. https://doi.org/10.1249/MSS.0000000000002370 
Vogt, M., \& Hoppeler, H. H. (2014). Eccentric exercise: Mechanisms and effects when used as training regime or training adjunct. Journal of Applied Physiology (Bethesda, Md.: 1985), 116(11), 1446-1454. https://doi.org/10.1152/japplphysiol.00146.2013

\section{(c) $(\mathrm{B})(\mathrm{EY}$}

This work is licensed under a Attribution-NonCommercial-NoDerivatives 4.0 International (CC BY-NC-ND 4.0). 